\title{
Study on Reader Service Mode of Higher Vocational College Library Based on Smart Campus
}

\author{
Zheng Xu \\ Qingdao Technical College. \\ 653872538@qq.com
}

\begin{abstract}
With the continuous development of science and technology and the popularity of the Internet, more and higher vocational colleges have carried out the research and construction of smart campus. As an important part of the construction of a smart campus, the construction of libraries has been valued by many higher vocational colleges. The most important thing for the wisdom of the library is the wisdom of the service model. This paper, under the support of smart campus theory, elaborates the improvement of library services through the construction of smart campus, and analyzes the existing problems in the library of higher vocational colleges, and puts forward suggestions and countermeasures for library construction under the construction of smart campus.
\end{abstract}

Keywords: Smart campus, reader service mode, library.

\section{Introduction}

With the rapid development of information technology in recent years, our lives have gradually entered the era of wisdom. This wisdom model is not only reflected in daily life, but also gradually emerged in the campus construction of higher vocational colleges. Many colleges and universities closely follow the development trend of the times and have carried out the construction of a "smart campus", thereby realizing the sharing of resources on the basis of the traditional campus network and realizing the informatization of school teaching, scientific research and management, thus providing convenience for teachers and students. As the important information storage department of the school, the library also needs to follow the trend of the times and conduct information construction. In the context of the school building a "smart campus", the library can integrate library information into the school information platform, change the traditional service concept of the library, improve the library's reader service, and form a wisdom service model that can provide services according to the needs of readers, and to meet the diverse needs of the majority of teachers and students in the school, this brings a new model to the reader service work of the academic library.

\section{Smart Campus and Reader Service Mode of Library}

\subsection{Smart Campus}

As an emerging concept, smart campus does not currently have a specific concept. Smart campus refers to the use of the advanced technology of the Internet of Things (IoT) on the basis of the Internet to integrate research, teaching, service, and campus life in universities, and adopts cloud computing and the latest information technology to integrate students, teachers and physical facilities such as computers, books, and classrooms. Smart campus uses the concept of smart services to create a new smart campus based on resource sharing [1]. The construction of a smart campus can integrate the information of various departments within the university to achieve effective use of resources. At present, major universities and colleges are actively participating in the research and construction of smart campus. Such universities as Zhejiang University and Chengdu University have already been completed and implemented in the smart campus construction project.

The construction of a smart campus includes all aspects. In teaching, the teaching methods of the smart campus are mainly data-based, with features such as openness, energy saving, and convenience. It is not only convenient for teachers to exchange information on teaching content and methods, but also enables teachers to more easily understand the true situation of students' understanding of knowledge. In terms of school management, smart campuses can concentrate on information 
integration to make management more centralized and avoid the problems of decentralization of various departments in traditional college management.

\subsection{Reader Service Mode of Library}

The library reader service model includes research reader service model and reading reader service model. At the same time, the library service model can also be divided into two categories, namely, the standardized service model and the personalized service model. Library standardization services refer to library books borrowing, reading and consulting, literature information retrieval and inquiry services, reader education and training, and other service processes. For example, the standardization service of the consulting office includes answering questions concerning the use of library collections and service items; conducting various information retrieval services for readers; handling the issue of borrowing cards, re-issuance, loss reporting, recovery, and book loss compensation and other specific issues. The personalized service model is reader-oriented, and adopts different service methods for different readers based on the differences in readership levels and requirements. Including the requirements of the reading room environment, the requirements of the books, the requirements for service terms, the handling of accidental accidents in the service process, etc., the remarks and behaviors of the staff can all reflect the personalized service. In short, on the basis of doing a standardized service, we must also meet the reader's needs to the maximum extent possible.

\subsection{The Improvement of Library Services Through the Construction of Smart Campus}

Under the premise of building a smart campus, the library can provide teachers and students with a platform for information inquiry and information gathering. Schools can effectively share information resources through the information platform of the library website. In the library's website, teachers and students can consult relevant materials in the literature or search for bibliographic information. At the same time, due to the establishment of the database, under the digital library, it is possible to judge readers' hobbies and personal needs based on readers' borrowing, reading and browsing records, and optimize the library's services. At the same time, the library website can efficiently organize the various sections and departments of the library website according to the different needs of the users, thus avoiding the disadvantages of low efficiency and slow processing speed of the traditional library management, and fully implementing the role of various library departments. For research readers, library resources can be classified according to their research content, which is convenient for readers to consult.

The unified platform constructed by the smart campus has integrated the information of the library with other departments, improved the quality of library services through the understanding of readers' habits, and promoted the personalization of the library on the basis of ensuring standardized library services.

\section{The Existing Problems in the Current Reader Service of Higher Vocational College Libraries}

\subsection{Poor Service Attitude}

At present, the common problem of library service in higher vocational colleges is poor service attitude. The librarian's idea still stays in the era of "as long as it is possible to manage the books" and the service attitude is poor. Not only can the questions raised by readers fail to be answered effectively, but also the lack of active service awareness, which makes the lack of the understanding of the reading habits of readership in the service process. This has created a vicious circle. This makes many students reluctant to go to the library to access information.

\subsection{Old Library Collection}

The library literature of higher vocational college is relatively old. The completeness of the library's books is directly related to whether the library can attract readers. At present, because the 
higher vocational college library has not received enough attention from the school, many books can no longer meet the current needs. And in the process of book purchase, because of the problem of service model, it fails to understand the current needs of readers in a timely manner, resulting in books purchased by libraries merely increasing the amount of library collections. At the same time, because the library's electronic retrieval system is not fully utilized, students are also faced with difficulties in the process of searching books, which make fewer students read in the library.

\subsection{The Problems of the Library Personalized Service}

Library personalized service does not meet the needs of readers. In the context of the global information age, many libraries of higher vocational colleges still remain in the service mode of "borrowing and returning books" in traditional libraries. This model does not meet the current student needs for information. Due to the rapid spread of the Internet, most of the literature needed by students is available via the Internet. At present, the library of higher vocational colleges and universities does not timely develop network services for individual needs of students.

\subsection{The Publicity of the Library}

The propaganda of the library is not enough. Although both teachers and students know the existence of the school library, the specific literature resources in the library are not very clear. This requires the library to carry out propaganda in a timely manner, and regularly carry out certain activities to publicize and guide the readers, and display rich resources and services to the teachers and students of the whole school. Many higher vocational college libraries have not done enough in publicity. Some readers only know that libraries can borrow books. They don't know how to use library electronic information resources. Some people do not know how to search, which results in a waste of library resources.

\section{The Suggestions and Countermeasures for Library Construction Under the Construction of Smart Campus}

The reader service model of higher vocational college libraries based on smart campus is a brandnew service model. It integrates the intelligent librarian's knowledge services and is an expert system service that provides in-depth knowledge mining of various information resources, open access resources, and personalized knowledge resources of university libraries, as well as features that analyze user needs. It is a high-level service with high quality, high value and deep content [2].

\subsection{The Upgrade of Library Hardware Facilities}

Due to the widespread problems in the hardware of current higher vocational college libraries, in order to meet the needs of smart campus construction, upgrading library services requires upgrading the hardware facilities of the library. The "smart campus" is constructed through the Internet of Things, wireless sensor technology, and cloud computing technology as a service method [3]. It integrates physical resources and network resources of the library in a variety of ways to make retrieval more convenient. At the same time, in addition to the information that can be retrieved in the library, it can also conduct in-depth knowledge mining based on the needs of readers, provide readers with other resource information and related services, and meet readers' multiple needs. At the same time, the wireless sensor technology and the Internet of Things are applied. The university library can record readers' reading behavior and analyze the information needs of readers through relevant analysis tools to provide readers with personalized and comprehensive solutions. Other aspects of the library should also increase its construction efforts, such as improving the reader's comfort by optimizing the reading environment of the library. At the same time, the entire hall is covered with Wi-Fi so that readers can access information anytime and anywhere. While these measures further enhance the user experience, they also reflect the library's service capabilities. 


\subsection{The Offer of High Quality Personalized Service}

Personalized services include smart management services, smart location services, smart guide services, self-service, and environmental and security services [4]. These services can improve the library's services and optimize the reader's experience. Using the Internet of Things technology in the library of higher vocational colleges, with the help of intelligent positioning services, readers can quickly find the books and reading rooms they need. This also makes the work of library managers more convenient and quick. Through the Internet of Things technology, readers can use their own capabilities to find library resources. Self-service makes the library's human and material resources fully utilized, while also saving the reader's time. The personalized service can provide relevant library information according to the students' professional and hobbies, which can better meet the needs of different students and improve the personalized service quality of university libraries. At the same time, with the support of the network, personalized services can divide different readers into different groups, and then provide relevant professional and subject information according to different groups. The network environment that exists everywhere brings great enrichment and convenience of information resources, changes traditional service concepts, fully exploits integrated network resources, and increases the openness of knowledge and information resources to provide readers with convenient and personalized services.

\section{Summary}

In the background of the current era, the construction of a smart campus is an important step in the informationization of higher vocational colleges. The construction of a smart campus has also brought about a tremendous improvement in the service model of the library of higher vocational colleges. As the construction of smart campuses in higher vocational colleges has just started, the informationization of libraries is gradually being realized, and there are also many problems. Faced with these problems, we must reasonably plan and integrate resources, upgrade library hardware and software, and gradually upgrade the services of higher vocational college libraries so that libraries can better serve teachers and students.

\section{References}

[1]. Liu Beixuan. "On the New Service Mode of University Library under the Smart Campus Mode" Journal of Qingyuan Vocational and Technical College 10.3(2017): 79-82.

[2]. Wu En. "The Construction of Smart Library and Its Service Model." Information and Documentation Work 33.5 (2012): 102-104.

[3]. Yin Kevin, and Zhang Lixin. "Study on the Service Model of University Library Based on Wisdom Library." Library Work and Research 9 (2017): 109-113.

[4]. Liu Xinhua. "Individualized Services of University Libraries Based on Internet of Things." Science and Technology Wind 12 (2018).

[5]. Hour Fula. "The Exploration of Reader Services in University Libraries under the Ubiquitous Network Environment” Agricultural Network Information 7 (2016): 93-95. 